\title{
Formações continuadas de professores alfabetizadores e concepções que as permeiam
}

\author{
Aline Pereira Ramirez Barbosa
}

Beatriz Salemme Corrêa Cortela

\section{Resumo}

O presente artigo tem como objetivos refletir sobre alguns cursos de formação continuada (FC) oferecidos nas duas últimas décadas a professores alfabetizadores do estado de São Paulo e estabelecer relações a partir dos depoimentos de professores alfabetizadores a respeito de um curso de FC com conteúdo de Geometria oferecido pelo Pacto Nacional pela Alfabetização na idade certa-PNAIC. Entende-se que as concepções formativas adotadas nestes cursos são norteadas por políticas públicas educacionais que, a princípio, parecem diferentes, mas que convergem para os mesmos propósitos. A partir de análises qualitativas, foi realizada uma breve explanação sobre cinco programas de $\mathrm{FC}$ de professores voltados à alfabetização: Programa de Formação de Professores Alfabetizadores (PROFA); Programa Pró-letramento; Programa Letra e Vida; Programa Ler e Escrever; e PNAIC, relacionando-os aos modelos formativos adotados em diferentes momentos por uma rede municipal de ensino, situada no interior do estado de São Paulo. Os resultados apontaram que os cursos adotam concepções tecnicistas de ensino e reproduzem ações formativas que podem aligeirar o processo de apropriação teórica e metodológica, influenciando o processo de ensino. Nota-se, a partir das respostas dos sujeitos ouvidos, que o modelo tecnicista que enviesa tais formações é considerado positivo por ser prescritivo, mesmo que desconsidere as dificuldades conceituais dos professores que irão proceder as ações.

Palavras-chave: Formação continuada de professores alfabetizadores. Modelos de formação. Estrutura de cursos. 


\title{
Continuing education of literacy teachers and its underlying conceptions
}

\author{
Aline Pereira Ramirez Barbosa
}

Beatriz Salemme Corrêa Cortela

\section{Abstract}

The goals of this article is, first, to reflect about some continuing education courses (CF) offered in the past two decades to literacy teachers from the Sao Paulo State and, second, to establish some relations from the testimony of literacy teachers toward one CE course regarding Geometry offered by the National Pact for Literacy at the Right Age (known in Brazil as PNAIC). We understand that the formative conceptions adopted in these courses are guided by educational public policies that, in principle, seems different, but that converts to the same purposes. Based on qualitative analyzes, we gave a brief explanation about five CE programs for teachers focused on literacy levels of education: Literacy Teacher Formation Program (PROFA); Proliteracy Program; Letter and Life Program; Read and Write Program; and PNAIC, relating them to the formative models adopted in different times for a municipal school system, located in the Sao Paulo State interior. The results point out that the courses adopted Technical Education conceptions of teaching and that they reproduce formative actions that can lighten the process of theorical and methodological appropriation, influencing the teaching process. We noted, from the answers given by the teachers interviewed, that the technical education model that has biased these formations is considered positive for being prescriptive, even though it did not consider the conceptual difficulties of the teachers that will promote those actions.

Keywords: Continuing Education of literacy teachers. Education Model. Course structure. 


\section{Introdução}

Este estudo é um recorte da dissertação de mestrado da primeira autora que, em suma, visou compreender como se procedeu e quais foram os impactos de um curso de formação continuada sobre Geometria, desenvolvido pelo Pacto Nacional pela Alfabetização na Idade Certa (PNAIC), realizado em 2014, nas práticas de ensino cinco professoras que, à época, lecionavam para os anos iniciais do Ensino Fundamental de uma mesma rede de ensino, situada no interior do estado de São Paulo. Para tanto, fez-se necessário revisitar os processos formativos pelos quais aqueles sujeitos de pesquisas (professores alfabetizadores) tiveram acesso (ou contato) ao longo de seus anos de magistério, seja de maneira direta como participantes (cursistas) ou de maneira indireta, nos momentos destinados às trocas de experiências entre os pares.

Um ponto comum na rotina do planejamento escolar nesta rede de ensino é que coordenadores pedagógicos e professores são chamados a apresentarem suas estratégias de ensino uns aos outros ao longo dos anos letivos e estas sofrem (e sofreram) a influências das diversas formações das quais fizeram parte. Considerando a efetividade destas práticas, todo o grupo de professores envolvidos interferem nas decisões individuais sobre o ensino. Assim, todas as formações, de certo modo, refletem no fazer docente em uma instituição escolar.

Desta forma, foi feita uma retrospectiva quanto aos diversos programas presentes na formação em serviço oferecida pelo Estado de São Paulo, nas duas últimas décadas, aos professores dos anos iniciais do Ensino Fundamental, com a perspectiva de compreender as propostas, apontando possibilidades para superação de dificuldades de ensino sobre diversos temas, entre eles, o ensino de Geometria.

Descrevem-se aqui, cinco programas de formação continuada (FC) de professores voltados à alfabetização: Programa de Formação de Professores Alfabetizadores (PROFA); Programa Pró-letramento; Programa Letra e Vida; Programa Ler e Escrever; e Pacto Nacional pela Alfabetização na Idade Certa (PNAIC), com o intuito de identificar e discutir as concepções que permeiam essas formações, seus pontos em comuns, os divergentes e seus potenciais formativos com vistas a traçar uma relação com a maneira como professores alfabetizadores compreenderam essas formações, tendo como base os depoimentos de cinco deles sobre um curso de FC com conteúdo de Geometria oferecido pelo PNAIC.

Como aponta Tardif (2014) os saberes docentes são constituídos por um conjunto de representações a partir das quais os professores interpretam, compreendem e orientam sua profissão. Neste sentido, a temática envolvendo formação de professores, as políticas públicas educacionais e a constituição de saberes docentes vêm se desenvolvendo ao longo dos últimos anos, apontando para um campo frutífero de estudos e pesquisas.

Estes resultados são importantes no sentido que podem nortear próximas iniciativas de cursos de formação continuada, uma vez que explicita uma avaliação a respeito de ganhos 
e perdas ocorridas no processo, ou seja, aquilo que ficou da formação, detectado a partir da observação da prática de ensino de um grupo de professoras alfabetizadoras, e as lacunas apresentadas. (SOUZA, 2006).

Dentro do senso comum, pensa-se que a avaliação é a última etapa de um processo de execução de uma política pública. No entanto, a avaliação é processual e não apenas incide no produto final. Saravia, Ferrarezi (2006), por exemplo, indicam sete etapas que facilitam a observação da efetivação das políticas públicas. A começar pela agenda de políticas, que é a inclusão de determinada necessidade social ou questão em uma pauta de discussão; elaboração que, em suma, identifica e determina alternativas para a resolução do pleito; a formulação que estabelece, entre todas as alternativas levantadas, aquela que é considerada mais conveniente; a implementação, constituída pelo planejamento e organização dos órgãos administrativos, financeiros e sociais para executar a política; o acompanhamento, constituído pelo processo sistemático de supervisão e execução e, por fim, a avaliação referindo-se a mensuração, muitas vezes, quantitativas dos resultados produzidos. Ou seja, muitas vezes o aspecto qualitativo do processo avaliativo não é realizado de forma sistematizada.

Para realizar as avaliações das Políticas Educacionais no Brasil o MEC criou, em 1990, o Sistema de Avaliação da Educação Básica (SAEB), que avalia o rendimento dos alunos por meio de uma matriz de referência curricular, formulada com base no ensino por competência. Dentre outras avaliações externas, aplicadas em larga escala em nível básico, estão: a Provinha Brasil, instituída pelo MEC em 2005, o Exame Nacional do Ensino Médio (ENEM) e o Sistema de Avaliação do Rendimento Escolar do Estado de São Paulo (SARESP) no estado de São Paulo. Os dados obtidos com essas avaliações são amostrais e fornecem informações dos e aos sistemas de ensino, visando subsidiar as políticas públicas e também as instituições de ensino avaliadas. (GATTI et al., 2011).

Em 2007, o governo Federal criou o Índice de Desenvolvimento da Educação Básica (IDEB). Trata-se de um indicador utilizado para avaliar a qualidade do ensino de cada escola e da rede escolar, como um todo, calculado com base no rendimento do estudante avaliado por testes de larga escala, análise de taxas de aprovação e outros fatores, como absenteísmo, evasão e retenção (GATTI et al., 2011). O IDEB coloca-se como um desafio às redes escolares, quando delas se espera que tenham por meta um bom desempenho de seus alunos nas provas de larga escala, além de tentar garantir que os mesmos as realizem.

Essas avaliações direcionam, de forma intensa, as políticas públicas educacionais e influenciam as decisões sobre a continuidade, ou não, de um programa. Os cursos de formação continuada oferecidos aos professores também são por estas influenciados e, geralmente, partem de problemáticas encontradas nos resultados dessas avaliações para desenvolver suas ações e metas. 
Apresenta-se, a seguir, uma síntese de cinco formações continuadas em âmbito nacional, estadual e do município em questão. Como exposto anteriormente, as análises realizadas nos permitiram constatar as concepções que permeiam esses cursos, as influências destas formações na trajetória educativa dos professores e alguns fatores comuns entre elas. Conforme apontado pela Barbosa (2017), em uma de suas conclusões, estas concepções direcionaram as práticas de ensino dos professores do ciclo de alfabetização, sujeitos de sua pesquisa, coadunando com Nóvoa (1992), ao afirmar que, paralelamente ao fazer docente, o professor vivencia processos que influenciam seu agir, teórico e metodológico.

\section{A análise de cursos de formação continuada oferecidos a professores alfabetizadores}

O campo de estudos relacionado à formação de professores é muito amplo, sinalizam avanços e evidenciam questões emergentes. Os contextos sociais, políticos, econômicos, culturais, tecnológicos, assim como a democratização do ensino, trouxeram inúmeras transformações ao cenário educacional brasileiro nas últimas décadas.

A questão da formação continuada de professores tem sido um grande desafio para as políticas educacionais. Houve uma grande expansão das redes de ensino em curto espaço de tempo e, consequentemente, a ampliação da necessidade de formação de professores, tanto inicial quanto em serviço. No entanto, Gatti (2008), baseada em seus estudos e observações sobre os resultados das avaliações das políticas públicas para formação continuada da última década (meados dos anos 90 a 2008) verificou que as mesmas não contribuíram para mudanças expressivas nos desempenhos dos alunos nas avaliações em larga escala. Acredita, a autora supracitada, que isso decorre do fato de que os administradores públicos, em diferentes níveis, não contemplaram a Educação e a carreira dos professores “[...] com políticas coerentes com as necessidades de um país que se quer socialmente avançado” (GATTI, 2011, p.1). Neste sentido, conclui que os gestores da Educação têm que desenvolver novas perspectivas e saber implementá-las, visando distanciar os alunos do fracasso escolar, rumo ao avanço social possível de se estabelecer a partir da democratização do conhecimento.

Atualmente, os propósitos que são colocados para a Formação Continuada são diversos e visam atingir algumas problemáticas, tais como

[...] de sanar dificuldades escolares que acontecem no cotidiano escolar; de implantar políticas, programas, projetos, campanhas, principalmente governamentais; de adquirir certificados (créditos) para ascender na carreira e/ou obter benefícios salariais; de satisfazer interesses ou necessidades de conhecimentos específicos, ou seja, cursos de curta duração que contribuem apenas para cumprir uma exigência social. (ALVARADO-PRADA, FREITAS; FREITAS, 2010, p. 374).

Os autores supracitados indicaram que foi a partir dessas condições que se configurou um quadro formativo em que expressões como 'capacitação', 'treinamento', 'reciclagem', ISSN 2526-2882 
'aperfeiçoamento', entre outras, passaram a identificar alguns destes processos formativos de acordo com suas respectivas características, com "[...] uma ideologia e uma concepção tecnicista da educação que apresentam preocupação com a eficácia e a eficiência na educação tal como acontece na indústria, no comércio e no mercado de capitais, cujo foco principal é apenas o lucro" (ALVARADO-PRADA, et al., 2010, p. 375). Sob essa perspectiva, os professores são considerados meros executores de tarefas, não lhes sendo permitida a autoria dentro do processo educativo, o que lhes dificulta/impossibilita gerir sua própria aprendizagem.

Alvarado-Prada et al. (2010) verificaram que há outro fator que tem contribuído para o insucesso de algumas propostas de formação continuada: a hierarquização entre os campos do conhecimento teórico e prático. Para os autores há uma supervalorização do conhecimento do saber teórico mediante ao saber da prática deixando, muitas vezes, de primar pelo conhecimento que é produzido pelo professor em seu contexto de trabalho, chamado por Gauthier et al. (1998) de saber experiencial, saber este ainda não validado pela academia.

Como consequência desta situação, pode ocorrer o empobrecimento das ações de formação de professores em exercício, na medida em que essa hierarquização atrapalha tanto o planejamento como a condução dos processos formativos, em razão da inadequação dessas ações frente às necessidades reais de um determinado grupo de professores pertencentes a um contexto específico.

Coaduna-se com Nóvoa (1992, p.25) ao apontar que “[...] a formação não se constrói por acumulação (de cursos, de conhecimentos ou de técnicas), mas sim através de um trabalho de reflexividade crítica sobre as práticas de (re)construção permanente de uma identidade pessoal. Logo, defende-se que é importante investir na profissionalização docente, valorizar os saberes da experiência, bem como a troca de experiência entre os pares.

Desta forma, a partir de uma abordagem qualitativa, as análises abaixo descrevem, sucintamente, cinco programas de formação continuada de professores, de âmbito nacional e estadual, pelos quais os professores alfabetizadores de uma rede municipal de ensino de uma cidade do interior do estado de SP tiveram acesso, direta ou indiretamente, nas duas últimas décadas. Partindo de resultados de pesquisa (BARBOSA, 2017) é traçado uma breve relação com a maneira como professores alfabetizadores compreendem essas formações, tendo como base os depoimentos sobre um curso de FC com conteúdo de Geometria oferecido pelo PNAIC.

\section{Programa de Formação de Professores Alfabetizadores- PROFA}

Este curso foi idealizado em 1999, por uma iniciativa do Ministério da Educação (MEC) e teve seu material didático produzido em 2000. Foi uma estratégia formativa de âmbito nacional, resultado de um processo iniciado com o lançamento dos Parâmetros Curriculares Nacionais (PCN) e que pretendeu contribuir para a superação de dois problemas: a formação inadequada dos professores e de seus formadores, e a falta de referências de 
qualidade para o planejamento de propostas pedagógicas que atendessem às necessidades de aprendizagem dos alunos - situações didáticas e materiais adequados. (BRASIL, 2001). Pretendeu socializar o conhecimento didático sobre alfabetização, disponível à época, e reafirmar a importância da implementação de políticas públicas destinadas a assegurar o desenvolvimento profissional de professores.

Este programa funcionou sob a supervisão da Profa. Dra. Telma Weisz e teve por objetivos: orientar os docentes, que lecionavam nos anos iniciais e na Educação de Jovens e Adultos (EJA), a modificar as situações de ensino e aprendizagem e a fundamentar suas ações em salas de aula heterogêneas, conscientizando-os das necessidades da reflexão e do trabalho coletivo. O modelo teórico metodológico adotado foi o construtivista, na perspectiva piagetiana, e que visava "[...] deslegitimar a prática tradicional de ensino construída por inúmeros professores ao longo de suas carreiras e de suas formações, em favor da legitimação e da absorção mecânica e puramente passiva” (RAMOS; FERRAONI, 2009, p.73).

Adotar essa definição metodológica vinculou o programa à ideia do novo, do contemporâneo e de indispensável para a melhoria da Educação Básica do país, fundamentalmente, por sua atualidade e reconhecida base teórica sobre alfabetização, oriunda dos estudos de Emília Ferreiro e Ana Teberosky (1999), pautadas em trabalhos de Piaget.

Sob slogans, como "É preciso mudar" ou "É preciso reconstruir toda a prática a partir de um novo paradigma teórico" (BRASIL, 2001, p. 81), o PROFA conduz seu cursista à compreensão de que o único meio para se chegar a essa melhoria da educação seria pela adoção e utilização, em sala de aula, dos preceitos construtivistas e da consequente negação daquilo que é ligado ao modelo tradicional. (RAMOS; FERRAONI, 2009, p.77).

Sob as orientações de Weisz surgiu uma concepção metodológica que fundamentou o programa e o material do curso: a constituição de vídeos com filmagens de situações de ensino e apostilas com conteúdos pertinentes à alfabetização da língua materna. Todo o material foi oferecido pelo programa e entregue aos professores, exceto os vídeos, que foram exibidos durante o curso, totalizando trinta filmagens.

Anteriormente à entrega do material e ao início do curso, ocorreu a preparação dos formadores que, geralmente, eram orientadores ou coordenadores pedagógicos do município ou do Estado. Essa formação inicialmente foi oferecida pelo MEC; porém, após o ano de 2002, coube aos municípios e aos Estados que adotaram o programa, orientar e preparar seus formadores para que estes socializassem as propostas e concepções do programa aos professores alfabetizadores. Neste processo, que em muito se assemelha à brincadeira do "telefone sem fio" ${ }^{21}$, podem ter ocorrido reducionismo e deturpações de conteúdos e estratégias que resultaram em perdas no processo formativo.

21Trata-se de uma tradicional brincadeira popular, na qual uma pessoa fala uma palavra ou frase (o "segredo") ao ouvido de outra pessoa ao seu lado, de modo que os demais participantes não escutem ou ISSN 2526-2882

$$
316 *
$$


A carga horária dessa formação foi de 160 horas das quais, parte dela (75\%), foi destinada aos trabalhos em grupo. As demais horas deveriam ser cumpridas levando em consideração o trabalho do professor e suas ações em sala de aula. Este programa foi um marco nas políticas públicas educacionais, pois foi o primeiro a propor formação continuada a professores alfabetizadores e voltar o olhar para essa temática. Foi extinto em 2003, após mudança governamental no país e a criação de outras diretrizes para a Educação Básica, como será apresentado a seguir.

Cabe também lembrar que esta formação subsidiou um programa semelhante chamado "Letra e Vida", implantado no estado de São Paulo e no município pesquisado, em 2003, ainda sob supervisão de Weisz, e que será apresentado nos próximos itens.

\section{Pró-letramento}

O Pró-Letramento é um programa de formação continuada para professores, de âmbito nacional, atualmente ativo e que visa a melhoria da qualidade do ensino e da aprendizagem, abrangendo as áreas da leitura, da escrita e da Matemática básica para os anos iniciais da Educação Básica. Foi criado em 2006 pelo MEC, em parceria com universidades que integram a Rede Nacional de Formação Continuada ${ }^{22}$ com a finalidade de aperfeiçoar o ensino de Língua Portuguesa e Matemática, sendo o primeiro programa que visou o ensino destes conteúdos para os anos iniciais. Foi oferecido na modalidade de formação continuada a distância intencionando apoiar o trabalho pedagógico desenvolvido pelos professores que atuavam no Ensino Fundamental I.

A origem dessa ação de formação continuada do Governo Federal está diretamente relacionada com o projeto político que ampliou de oito para nove anos a duração do Ensino Fundamental no país - nível de ensino que, pela legislação brasileira, deve ser universal e obrigatoriamente ofertado pelo Estado. Tal ampliação complementou a Lei n. 11.274, de 06/02/2006, em vigor, que prevê a entrada nesse nível de ensino das crianças com seis anos de idade e um período de transição de quatro anos para as redes públicas se adequarem à nova normatização do Ensino Básico. (BRASIL, 2006). Tal medida aumentou o tempo de escolarização, tendo como argumentos a intenção de promover uma reflexão sobre a cultura

descubram imediatamente qual é. Quem ouviu o segredo tenta então repeti-lo para o próximo participante e assim por diante, até chegar ao último, que deve contar o que foi dito inicialmente em voz alta. Em geral, é comum o segredo ser mal entendido por ter sido passado aos demais ouvintes de forma deturpada, chegando totalmente diferente ao ouvinte final. (Adaptado, Revista Crescer, jun.2016, disponível em http://revistacrescer.globo.com/Revista/Crescer/o,EMI783-10528,oo.html)

${ }^{22} \mathrm{O}$ Centro de Formação Continuada em Educação Matemática e Científica da Universidade Federal do Espírito Santo- CeFoCo Matemática e Ciências, 2. Laboratório de Pesquisa e Desenvolvimento em Ensino de Ciências e Matemática- LIMC /UFRJ, 3. Núcleo de Formação Continuada de Profissionais da Educação - NUPE/UNISINOS, 4. Centro de Educação Continuada em Educação Matemática, Científica e Ambiental- CECEMCA/UNESP e 5. Formação, Tecnologia e Prestação de Serviços em Educação em Ciências e Matemáticas- EDUCIMAT/UFPA. 
pedagógica da alfabetização no Ensino Fundamental e reverter resultados negativos das avaliações externas, nacionais e regionais, da Educação Básica.

As abordagens teóricas e didáticas do referido curso apoiam-se na perspectiva da alfabetização e letramento, que sinteticamente considera que "[...] há uma diferença entre saber ler e escrever, ser alfabetizado, e viver na condição ou estado de quem sabe ler e escrever, ser letrado [...]” (SOARES, 1999, p.3). Segundo a autora, a alfabetização na perspectiva do letramento é um "[...] resultado da ação de ensinar e aprender as práticas sociais de leitura e de escrita" (SOARES, 1999, p.4). Neste curso pretende-se subsidiar o trabalho docente de modo que este conheça e desenvolva ações didáticas que envolvam as práticas sociais da leitura, da escrita e dos conhecimentos matemáticos, tornando seus alunos letrados, ou seja, capazes de apropriar-se dos conhecimentos em Língua Portuguesa e Matemática para relacioná-lo ao mundo que o cerca. A intenção é proporcionar formação, acompanhamento e oferecer estratégias de ensino ao docente que os possibilite ministrar as relações entre os conhecimentos científicos e seus diferentes usos sociais.

Podem participar do pró-letramento professores em exercício, desde que estejam vinculados ao sistema público de ensino, que trabalhem em classes dos anos iniciais do ensino fundamental ( $1^{\mathrm{a}}$ a $4^{\mathrm{a}}$ série ou $1^{\mathrm{o}}$ ao $5^{\mathrm{o}}$ ano), e que possam participar das reuniões com o tutor para discutir os textos lidos, retomar as atividades realizadas e planejar as futuras ações. $\mathrm{O}$ curso é mediado por tutores, que são professores selecionados dentro da própria rede pública de ensino e com formação em nível superior. A carga horária para os professores cursistas é de 120 horas, sendo 84 horas presenciais e 36 horas a distância, divididas entre os conteúdos de Matemática e Língua Portuguesa.

Para a realização do curso, cada professor/cursista recebe um kit de materiais com um Guia do Curso e fascículos englobando a Língua Portuguesa e a Matemática que norteiam seus estudos ${ }^{23}$. Estes textos são estudados e discutidos em encontros quinzenais e propõem ações para reflexão da prática docente, bem como, o registro das atividades aplicadas.

O curso oferecido apoia-se em um modelo formativo semipresencial, que visa também promover a formação de tutores locais em encontros presenciais nos diversos estados do país. De acordo com Silva e Cafieiro (2010), esses tutores têm como função o planejamento e a execução do mesmo modelo de curso que realizam com as universidades, agora voltados para turmas de, no máximo, 50 professores de sua região, com o auxílio de coordenadores indicados pelas Secretarias de Educação.

23Os materiais para o Pró-Letramento em Matemática foram desenvolvidos pelos professores dos cinco Centros de Formação Continuada em Educação Matemática e Científica da Rede Nacional de Formação Continuada que focou na problematização dos conteúdos e nas práticas cotidianas dos professores/cursistas em sala de aula. 
Trata-se, portanto, de um modelo de formação em rede com ações de formação simultâneas: tutores, à medida que se formam, repassam os conhecimentos. Vale lembrar que a aprendizagem destes tutores não se dá de maneira homogênea e sem deturpação, em maior ou menor grau. De acordo com Silva e Cafieiro (2010), desde o início da implementação do Pró-Letramento, a demanda pelo Programa aumentou de maneira expressiva. Assim, já em 2009, uma parte significativa das escolas de todo o Norte e o Nordeste do Brasil (onde o Programa foi implantado, prioritariamente) tinha sido atendida e, desde 2010, o PróLetramento passou a ser oferecido em todo o país.

\section{O programa Letra e Vida}

Este projeto, já extinto, teve início no ano de 2003 e estabeleceu parcerias com várias instituições educacionais federais, municipais, públicas e particulares, promovendo uma formação direcionada para alfabetização e o letramento.

Informações levantadas junto à Secretaria da Educação do Estado (SEE), (BRASIL, 2001), apontam que para compor o curso "Letra e Vida" e seus módulos, equipes foram montadas sob a coordenação da supervisora pedagógica Telma Weisz. Essas equipes foram responsáveis por produzir materiais midiáticos (vídeos com situações reais de alfabetização em sala de aula) e materiais impressos para auxiliar os momentos formativos e propor reflexões. Os objetivos do programa consistiam em

[...] melhorar significativamente os resultados da alfabetização no sistema de ensino estadual, tanto quantitativa quanto qualitativamente; contribuir para uma mudança de paradigma quanto à metodologia de formação dos professores; ampliar o universo cultural dos educadores para que se formem, na base do sistema estadual de educação, quadros estáveis de profissionais capazes de desenvolver a formação continuada de professores alfabetizadores. (BRASIL, 2003, s/p.)

Com o material elaborado, o Estado solicitou que cada município selecionasse professores formadores para receberem e repassarem a formação aos professores alfabetizadores, na forma conhecida como 'multiplicadores'. No município, lócus desta pesquisa, cujos resultados estão sendo discutidos, os professores formadores foram selecionados pelo departamento pedagógico da Secretaria Municipal de Educação para reproduzir os conhecimentos dessa formação nos moldes estabelecidos.

O material impresso era composto por duas apostilas, divididas em três módulos, com duração de um semestre cada. O primeiro módulo abordava conteúdos de fundamentação, relacionado aos processos de aprendizagem da leitura e da escrita; o segundo e terceiro trataram, especificamente, de propostas de ensino e aprendizagem da língua escrita na alfabetização.

Em cada encontro cinco atividades eram propostas aos cursistas, sendo que três delas eram permanentes e aconteciam em todos os encontros: 1-leitura compartilhada de textos 
literários; 2-rede de ideias: momento em que os participantes compartilhavam suas ideias, opiniões e dúvidas com os colegas, e 3-trabalho pessoal: composto por situações de leitura e escrita realizadas dentro e/ou fora do grupo. As atividades diversificadas giravam em torno da “[...] tematização da prática docente, planejamento metodológico e intercâmbio a partir do conhecimento experiencial" (BRASIL, 2003, p.20).

Todos os módulos iniciavam suas orientações destacando as competências a serem desenvolvidas pelos participantes, denominadas por "expectativas de aprendizagem". Tais expectativas norteavam a avaliação do cursista, realizada ao final de cada módulo. Ao todo, 48 competências foram estimuladas, entre elas:

Reconhecer a importância de ler diariamente bons textos para os alunos, compreendendo que esse tipo de prática requer planejamento, critérios de qualidade e diversidade para a seleção de textos e leitura prévia dos mesmos. [...]. Planejar intervenções adequadas. (Módulo 1) (BRASIL, 2003, s/p).

A metodologia do programa apoiava-se, fundamentalmente, no modelo teórico construtivista piagetiano, também inspirado nos modelos de Ferreiro e Teberosky, (1999) e nas estratégias de resolução de situações-problemas, na qual era verificada a produção dos alunos, simulação e planejamento de situações didáticas, segundo as orientações determinadas. A estratégia adotada com essa formação foi a de ensinar o professor a compreender as hipóteses de escrita em que seu aluno se encontrava (pré-silábico; silábico, sem valor sonoro; silábico, com valor sonoro; silábico-alfabético; e alfabético) e adotar a melhor estratégia para fazê-lo avançar.

Algumas ações docentes foram sugeridas e reforçadas nos momentos de formação, entre elas: agrupar os alunos em sala de aula de acordo com as diferentes hipóteses de escrita; promover ações de leitura diversificadas do tipo textos de memória, parlendas, diferentes gêneros; elaboração textos; e fazer listas de palavras.

Ao término de cada módulo, realizava-se uma avaliação dos resultados, composta de uma prova sobre conhecimentos didáticos trabalhados no programa e por meio de relatos reflexivos produzidos pelos cursistas.

Há de se ter em conta que aspectos como a supervisão do curso, o modelo construtivista adotado, a utilização de vídeos e a metodologia adotada no curso são bastante parecidos com aqueles desenvolvidos pelo Programa de Formação de Professores Alfabetizadores- PROFA, que foi extinto em 2003, em nível federal. Evidencia-se, neste sentido, que são os gestores das propostas que determinam, nas políticas públicas, as abordagens defendidas por grupos hegemônicos no poder. 
Apesar do potencial formativo do projeto em questão, resultados obtidos pelo SARESP 24 apontaram que ainda ocorriam muitas lacunas no que diz respeito à aprendizagem dos alunos, um descompasso entre o ensino de leitura e escrita, de acordo com indicadores provenientes das avaliações realizadas nos anos iniciais do ensino fundamental.

\section{O programa Ler e Escrever}

As avaliações de larga escala continuaram a indicar as dificuldades dos alunos na aquisição das competências e habilidades de leitura e escrita. A fim de nortear novas ações, em 19/12/2007, a partir da resolução da SEE, no 86, o governo paulista formulou outra política pública educacional e instituiu um novo programa de formação continuada de professores, denominado "Ler e Escrever", que objetivava solucionar e melhorar a qualidade de ensino, assim como oferecer recuperação de conteúdos aos alunos do ciclo I $\left(1^{\mathrm{a}}\right.$ a $4^{\mathrm{a}}$ série do Ensino Fundamental).Vale lembrar que desde 1994 o governo do Estado de São Paulo vem sendo ocupado por governadores do Partido da Social Democracia Brasileira (PSDB). São 24 anos de uma mesma agenda política, econômica, social e educacional, que, de acordo com pesquisadores já citados e com a mídia ${ }^{25}$, é uma decepção no que diz respeito à gestão da educação pública.

Nesse sentido, o programa "Ler e Escrever" partiu da observação dos ganhos e dificuldades do projeto anterior, concentrando esforços em manter o processo de alfabetização em pressupostos teóricos construtivistas. Porém, a principal mudança em relação ao programa anterior foi o envolvimento dos gestores escolares nas discussões relacionadas à alfabetização, bem como no acompanhamento da escola no tocante a alfabetização (BAUER, 2011).

[...] o Trio Gestor envolve os Supervisores, Diretores e ATPs que participarão das reuniões mensais e encontros com as formadoras do programa com o objetivo de aprenderem sobre o processo de alfabetização dos alunos, auxiliando os professores das escolas e os Professores Coordenadores do Ciclo I nos trabalhos realizados na alfabetização e na avaliação dos alunos. (SÃO PAULO, 2007, s/p.).

Outra ação diferenciada do programa "Ler e Escrever" referia-se à preparação, seleção e distribuição de materiais didáticos aos professores e alunos, uma espécie de guia com comandos ao trabalho do professor e atividades de alunos, reflexos do ensino tecnicista, ainda

24 Sistema de Avaliação de Rendimento Escolar do Estado de São Paulo (SARESP) é aplicado pela Secretaria da Educação do Estado de São Paulo com a finalidade de produzir um diagnóstico da situação da escolaridade básica paulista, visando orientar os gestores do ensino no monitoramento das políticas voltadas para a melhoria da qualidade educacional. Disponível em https://www.educacao.sp.gov.br/saresp, acesso em 16/05/2020

25O jornal Folha de S. Paulo publica um editorial em que define como 'decepção' a performance do partido na gestão da educação no estado; o jornal afirma que o PSDB é governo desde 1994 no estado de São Paulo - sendo Alckmin eleito três vezes - e que, portanto, não há como responsabilizar a descontinuidade como origem do péssimo resultado nos indicadores do ensino fundamental e médio. 05/09/2018 https://www1.folha.uol.com.br/opiniao/2018/o9/decepcao-tucana.shtml, acesso em $24 / 04 / 2019$. 
presente no processo formativo. Foram disponibilizados cadernos de orientações sobre o currículo do Estado de São Paulo para as disciplinas de Língua Portuguesa e Matemática para professores regentes, professores coordenadores e diretores de $1^{\mathrm{a}}$ a $4^{\mathrm{a}}$ séries do E.F; guias de planejamento e orientações didáticas para o professor alfabetizador; caderno de planejamento e avaliação do professor alfabetizador; além de cadernos com coletâneas de atividades do aluno; assinatura e aquisição de revistas e almanaques, livros paradidáticos, conjunto com letras móveis, entre outros recursos didáticos. As características apresentadas nestes guias curriculares não se distanciam do que Souza (2006, p.209), afirmou como sendo “[...] manual para o professor, como um receituário indicando conteúdo, tempo e avaliação, com detalhamento para controlar a prática docente”. Numa perspectiva tecnicista que parece ir em direção inversa da proposta nos referidos cadernos de formação, presente mais nos discursos que nas práticas propostas.

A rede municipal de ensino, aqui analisada, aderiu ao programa "Ler e Escrever" somente no ano de 2009 e, em suas formações, procurou unir os ideais do programa "Letra e Vida" e do programa "Ler e Escrever" a fim de promover uma unidade na formação. A equipe do departamento pedagógico municipal recebeu uma formação sobre esse novo programa, repassou aos coordenadores pedagógicos das escolas e coube a eles divulgar os preceitos dessa nova formação aos professores alfabetizadores, bem como as formas de utilização do material didático.

No ano de 2010, ocorreu a troca de gestão do governo da cidade estudada e uma nova secretária de Educação assumiu a pasta. Ocorreram também mudanças na equipe do departamento pedagógico e, no que se refere à formação de professores, foi estabelecida uma parceria com uma Universidade pública presente na cidade e, desta parceria, decorreu uma proposta formativa com base na perspectiva histórico-crítica abarcando "[...] a questão educacional com base no desenvolvimento histórico objetivo" (SAVIANI, 2013, p.76). Histórico, por compreender que a Educação também interfere sobre a sociedade, podendo contribuir para sua transformação, e crítica por ter consciência da determinação exercida pela sociedade sobre a Educação. A partir de então e até o presente momento, esta rede municipal de ensino passou a oferecer cursos/programas de formações continuadas aos professores guiados por essa nova vertente teórica, na contramão das formações construtivistas até então realizadas pelo Estado, agora dentro de uma perspectiva vigotskiana.

No ano de 2012, tal gestão adere à formação do Pacto Nacional pela Alfabetização na Idade Certa (PNAIC), que será explanado a seguir.

\section{O Pacto Nacional pela Alfabetização na Idade Certa- PNAIC}

Em 2012, como resposta às orientações do Plano Nacional de Educação (PNE), que objetivava alfabetizar as crianças até, no máximo, os oito anos de idade, final do $3^{\circ}$ ano do 
Ensino Fundamental, a portaria $\mathrm{n}^{0} 867$ de 04 de julho instituiu um programa denominado "Pacto Nacional pela Alfabetização na Idade Certa"-PNAIC, estabelecendo suas ações e diretrizes.

Com a criação desse programa, o Ministério da Educação (MEC) e as secretarias estaduais, distrital e municipais de Educação reafirmaram e ampliaram o compromisso com a alfabetização, comprometendo-se a avaliar os resultados dessa política educacional por meio de exame periódico específico, que será detalhado mais adiante. Neste sentido, o convite à participação do Pacto foi realizado a todos os municípios e Estados do país.

Por alfabetização, os textos deste programa consideram que se trata da compreensão do funcionamento do sistema de escrita, a fluência da leitura e o domínio de estratégias de compreensão de textos escritos, e produção textual dentro da perspectiva do letramento. A alfabetização matemática, em consonância com o material "[...] é entendida como um instrumento para leitura do mundo, uma perspectiva que supera a simples decodificação dos números e a resolução das quatro operações básicas” (BRASIL, 2014, p.5).

Para atender o objetivo principal do programa, o art. $5^{\circ}$ estabelece as expectativas do programa, (BRASIL, 2014, p.6), que são

I - garantir que todos os estudantes dos sistemas públicos de ensino estejam alfabetizados, em Língua Portuguesa e em Matemática, até o final do $3^{\circ}$ ano do ensino fundamental;

II - reduzir a distorção idade-série na Educação Básica;

III - melhorar o Índice de Desenvolvimento da Educação Básica (IDEB);

IV - contribuir para o aperfeiçoamento da formação dos professores alfabetizadores;

V - construir propostas para a definição dos direitos de aprendizagem e desenvolvimento das crianças nos três primeiros anos do ensino fundamental.

Quatro eixos de atuação foram elaborados para organizar o funcionamento e apoiar as ações do PNAIC: i. Gestão e mobilização de controle; ii. Material didático; iii. Formação continuada e seriada, e iv. Avaliações sistemáticas.

As gestões das ações do programa ficaram sob responsabilidade de um gestor nacional; uma coordenação institucional em cada Estado e no Distrito Federal; uma coordenação estadual, responsável pela implementação e monitoramento das ações em sua rede; e uma coordenação municipal, responsável pela implementação e monitoramento dessas ações.

Foi constituído um arranjo institucional, formado por comitês nacionais, estaduais e municipais para coordenar e avaliar as ações do pacto em todo o país. Também há um sistema de monitoramento disponibilizado pelo MEC, criado pelo Sistema de Monitoramento do Pacto Nacional pela alfabetização na Idade Certa (SisPacto), que apoia as redes de ensino e assegura a implementação das diferentes etapas do Pacto. Nesse processo, o MEC também deu ênfase 
ao fortalecimento dos Conselhos de Educação, dos conselhos escolares e de outras instâncias comprometidas com a Educação de qualidade nos estados e municípios.

O eixo 'material didático e pedagógico' refere-se às obras literárias de apoio pedagógico, aos jogos e tecnologias educacionais específicos para alfabetização e que são disponibilizados aos professores e às escolas participantes. Os livros didáticos são escolhidos pelos professores em suas escolas e entregues pelo Programa Nacional do Livro Didático (PNLD), com seus respectivos manuais. Coube ao PNLD a responsabilidade de indicar obras pedagógicas complementares aos livros didáticos e distribuir dicionários de Língua Portuguesa, além de jogos e software de alfabetização.

O Programa Nacional de Biblioteca na Escola (PNBE) distribuiu jogos pedagógicos de apoio à alfabetização, obras de referência de literatura e pesquisa. Cada turma do ciclo de alfabetização recebeu um acervo, criando uma biblioteca acessível às crianças e professores na própria sala de aula.

Este eixo também é o responsável pela seleção, elaboração e distribuição dos cadernos de formação aos professores, disponível nas formações dos anos de 2013 a 2015. Os autores dos cadernos foram os pesquisadores das universidades parceiras do programa, que possuem conhecimento e estudos científicos sobre a temática. Desta forma, cada caderno de formação contou com um grupo de autores que, baseados em referenciais teóricos e linhas de pesquisa diversas, desenvolveram a parte teórica do material. Professoras também foram convidadas a escreverem seus relatos de experiência, apresentando atividades exitosas, incluindo o conteúdo trabalhado naquele material. Os textos passavam por análises de um comitê gestor, consultores, pareceristas, leitores críticos e ainda contavam com as orientações de uma equipe de apoio pedagógico e consultoria.

No ano de 2013, foram elaborados oito cadernos de formação para o professor, focando a alfabetização em Língua Portuguesa, divididos em anos de ensino $\left(1^{\circ}, 2^{\circ}\right.$ e $3^{\circ}$ ano), além de um caderno de Alfabetização no Campo e outro de Educação Especial, que foram dispostos em 120 horas de formação.

Em 2014 o curso contou com 160 horas de duração, e para coordenar a produção dos cadernos de formação de Matemática, pesquisadores da Universidade Federal do Paraná foram convidados, considerando suas pesquisas na área de alfabetização matemática na perspectiva do letramento, bem como toda a experiência no programa Pró-letramento. Foram elaborados dez cadernos.

No ano de 2015, foram disponibilizadas 80 horas de formação e os cadernos de base para o curso abrangeram todas as áreas do currículo da Educação Básica, entre elas, Gestão educacional, Arte e Ciências e Interdisciplinaridade. Ao todo, foram elaborados 12 cadernos, no entanto, estes materiais apenas ficaram disponíveis para download na página do programa na internet. 
No ano de 2016 o curso foi desenvolvido em 100 horas abordando a temática de análise da matriz de referência da avaliação externa, “Avaliação Nacional da Alfabetização"ANA e os resultados por ela apontados nos anos de 2013 e 2014. Em 2017 com carga horária de 30 horas, as abordagens do curso concentraram-se na implementação de estratégias didáticas pedagógicas que efetivamente permitiriam às crianças, na concepção dos proponentes, a consolidação dos direitos, das competências e das habilidades de Leitura, Escrita e Matemática previstos para serem alcançados em cada ano do Ciclo de Alfabetização.

Em 2017, dispostas em 100 horas de duração, a proposta da formação foi a de revisitar conteúdos de Língua Portuguesa e Matemática, tais como: leitura, oralidade, espaço e forma, grandezas e medidas, entre outros, itens estes nos quais os alunos apresentaram baixo desempenho em resultados das avaliações externas.

Cabe ressaltar que a carga horária de formação deste curso foi distribuída em diferentes momentos formativos: uma parte da carga horária foi destinada para formações presenciais, outra parte para estudos em local de livre escolha, outra realizada a DistânciaEAD e a prática de ensino na escola. Para as formações presenciais foi destinada apenas uma pequena fatia do tempo total do curso. Por exemplo, a formação do PNAIC de 2018: das 100 horas do curso, apenas 20 horas foram destinadas ao curso presencial.

O terceiro eixo condutor do programa referia-se à formação continuada de professores alfabetizadores, sendo àqueles regentes das turmas do $1^{\circ}, 2^{\circ}$ e $3^{\circ}$ ano do $\mathrm{EF}$ e/ou também em classes multisseriadas. Para isso, o modelo formativo foi desenvolvido a partir de cursos, frutos da articulação entre universidades, Secretarias de Educação, escolas e professores atuantes nas salas de aula.

Para compor as formações, três grupos de professores foram selecionados: os formadores parceiros das Instituições de Ensino Superior (IES); os orientadores de estudo, que são professores selecionados pelas Secretarias de Educação local para receber a formação das IES e ministrar a formação; e os professores alfabetizadores das turmas regulares. Esse tripé, formado pelos três grupos de professores visava “[...] mobilizar diferentes saberes que se materializarão em práticas escolares que devem resultar em conhecimentos efetivos para as crianças" (BRASIL, 2014, p.11).

Entre os anos de 2013 a 2015 todos os envolvidos neste programa de formação continuada foram remunerados com bolsas de estudos autorizadas pela portaria $\mathrm{n}^{0} 90 \mathrm{de}, 6$ de fevereiro de 2013 e custeavam as ações desenvolvidas nessas formações. Conforme portaria $\mathrm{n}^{\mathrm{o}} 1.458$, de 14 de dezembro de 2012, art. $3^{\circ}, \S 1^{\circ}$ os recursos financeiros oriundos dessa rede formativa foram alocados diretamente dos orçamentos das Instituições de Ensino Superior (IES) ou transferidos por meio de descentralizações, convênios e outras formas de transferência. A partir das formações oferecidas em 2016 apenas os dois primeiros grupos contaram com a remuneração, e as formações dos professores alfabetizadores passaram a 
ocorrer durante o horário de trabalho, mais precisamente, nos momentos dedicados às Atividades de Trabalho Pedagógico Coletivo (ATPC).

Nos documentos explicativos do programa consta que os princípios desta formação continuada e suas ações são embasados no exercício da reflexividade do professor, pautados na análise da prática/teoria/prática, operacionalizada na reflexão de práticas de salas de aulas e na constituição da identidade profissional, bem como a valorização da socialização de experiências, fortalecimento de grupos de estudo, engajamento e o incentivo ao estudo, entre outros. (BRASIL, 2014). No entanto, como exposto anteriormente, a carga horária presencial é reduzida em relação às horas totais do curso e estes processos acabam sofrendo aligeiramentos e/ou reducionismos.

Sobre os princípios formativos, identificam-se traços de modelos de formações anteriores como, por exemplo, o programa "Letra e Vida”, que já trazia a prática da reflexividade por meio da problematização, e iniciava as formações resgatando as memórias educacionais do professor sobre determinado conteúdo. Outro ponto semelhante às formações anteriores, "PROFA" "Ler e Escrever" e "Letra e Vida" é a rede de formação criada, na qual um professor recebe a formação continuada e a repassa aos outros. Como já frisado, modelos estabelecidos dessa maneira podem gerar reducionismo e deturpações de conteúdos e estratégias, resultando em perdas não intencionais no processo formativo.

Percebe-se também que as orientações continuam responsabilizando o professor pela busca de competências profissionais e propõem que ele se adapte ao novo paradigma do século XXI, no qual os profissionais devem estar em constante aprendizado e submetidos a avaliações externas para verificar suas competências. Estando sujeito, inclusive, a sansões de diferentes ordens, quanto estas não são consideradas suficientes ou adequadas ao modelo vigente.

O último eixo estruturante do Pacto reúne três componentes principais para verificação da aplicabilidade e resultados do programa. São as avaliações realizadas durante o processo formativo e após a formação. Todos os custos referentes às avaliações externas são assumidos pelo MEC.

As avaliações contínuas, que são aquelas realizadas pelo professor com seus alunos durante todo ano letivo, também eram debatidas durante o curso de formação. Para essa, não há uma matriz a seguir. Trata-se de atividades elaboradas pelo professor, aplicadas aos seus alunos, com observação dos resultados obtidos. Neste sentido, as formações não contemplam aspectos importantes da avaliação da aprendizagem.

As avaliações externas sobre o processo de alfabetização decorrem da aplicação de uma prova em larga escala, denominada Provinha Brasil ${ }^{26}$, no início e final do $2^{\circ}$ ano do ensino

${ }^{26}$ Provinha Brasil são avaliações diagnósticas que visam identificar o desenvolvimento das atividades relativas à alfabetização e ao letramento em Língua Portuguesa e Matemática. São desenvolvidas com crianças do $2^{\mathrm{o}}$ ano do Ensino Fundamental no início e final do ano. Seus resultados devem funcionar ISSN 2526-2882

$$
326 *
$$


fundamental. O professor deveria inserir os resultados em um sistema informatizado para que gestores e professores acompanhem o desenvolvimento de aprendizagem de cada aluno e da turma, traçando os ajustes necessários à turma avaliada.

Já a avaliação universal era realizada no final do $3^{\circ}$ ano, com a aplicação de uma avaliação de larga escala denominada Avaliação Nacional da Alfabetização (ANA) coordenada pelo Instituto Nacional de Ensino e Pesquisa (INEP) e que objetivava avaliar o nível de alfabetização alcançado pelas crianças ao final do ciclo, identificando as lacunas com vistas a aprimorar o processo. Até a presente data o PNAIC está desativado, mas não há informações legais sobre sua extinção. A seguir, apresenta-se no quadro 3 uma síntese das políticas públicas oferecidas sob formações continuadas aos professores dos Anos Iniciais visando a melhoria do ensino e da aprendizagem no processo de alfabetização da língua materna e componentes da Matemática.

Quadro1- Síntese: Formações Continuadas de Professores em âmbito nacional e estadual

\begin{tabular}{|c|c|c|c|c|c|}
\hline & $\begin{array}{l}\text { PROF } \\
(2000-2003)\end{array}$ & $\begin{array}{l}\text { PRÓ- } \\
\text { LETRAMENTO } \\
\text { (2006-atual) }\end{array}$ & $\begin{array}{l}\text { PROGRAMA } \\
\text { LETRA E VIDA } \\
(2003-2007)\end{array}$ & $\begin{array}{l}\text { PROGRAMA LER } \\
\mathrm{E} \text { ESCREVER } \\
\text { (2007- atual) }\end{array}$ & $\begin{array}{l}\text { PNAIC } \\
\text { (2012-atual) }\end{array}$ \\
\hline Objetivos & 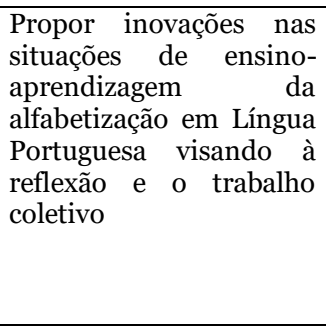 & $\begin{array}{lr}\text { Aperfeiçoar } & \text { o } \\
\text { ensino } & \text { de } \\
\text { Língua } & \\
\text { Portuguesa } & \text { e } \\
\text { Matemática } & \\
\text { nos anos } \\
\text { iniciais do } \\
\text { Ensino } \\
\text { Fundamental }\end{array}$ & $\begin{array}{l}\text { Melhorar } \\
\text { significativamente } \\
\text { os resultados da } \\
\text { alfabetização no } \\
\text { sistema de ensino } \\
\text { estadual, tanto } \\
\text { quantitativa } \\
\text { quanto } \\
\text { qualitativamente. }\end{array}$ & $\begin{array}{lr}\text { Solucionar } & \mathrm{e} \\
\text { melhorar } & \mathrm{a} \\
\text { qualidade } & \text { de } \\
\text { ensino, assim } & \text { como } \\
\text { oferecer } & \text { a } \\
\text { recuperação aos } \\
\text { alunos do ciclo I }\left(1^{\mathrm{a}}\right. \\
\text { a } 4^{\mathrm{a}} \text { série do } \\
\text { Ensino } \\
\text { Fundamental) }\end{array}$ & $\begin{array}{l}\text { Alfabetizar as } \\
\text { crianças em Língua } \\
\text { Portuguesa } \\
\text { Matemática até, no } \\
\text { máximo, os oito } \\
\text { anos de idade, final } \\
\text { do } 3^{\circ} \text { ano do } \\
\text { Ensino } \\
\text { Fundamental. }\end{array}$ \\
\hline Âmbito & Nacional & Nacional & Estadual (S.P) & Estadual (S.P.) & Nacional \\
\hline $\begin{array}{l}\text { Público } \\
\text { atendido }\end{array}$ & $\begin{array}{l}\text { Professores } \\
\text { alfabetizadores (anos } \\
\text { iniciais e Educação de } \\
\text { Jovens e Adultos) }\end{array}$ & $\begin{array}{l}\text { Professores do } \\
\text { Ensino } \\
\text { Fundamental I } \\
\left(1^{\mathrm{a}} \text { a } 4^{\mathrm{a}} \text { série ou }\right. \\
\left.1^{\mathrm{o}} \text { ao } 5^{\mathrm{o}} \text { ano }\right)\end{array}$ & $\begin{array}{l}\text { Professores dos } \\
\text { anos iniciais do } \\
\text { Ensino } \\
\text { Fundamental. }\end{array}$ & $\begin{array}{lr}\text { Professores } & \text { dos } \\
\text { anos iniciais } & \text { do } \\
\text { Ensino } & \\
\text { Fundamental } & \text { e } \\
\text { gestores } & \end{array}$ & $\begin{array}{l}\text { Professores dos } \\
\text { anos iniciais }\left(1^{\circ} \text { ao }\right. \\
3^{\circ} \text { ano do Ensino } \\
\text { Fundamental e, a } \\
\text { partir de 2016, } \\
\text { também } \\
\text { coordenadores } \\
\text { pedagógicos. }\end{array}$ \\
\hline $\begin{array}{l}\text { Concepção } \\
\text { teórica }\end{array}$ & $\begin{array}{l}\text { Construtivista } \\
\text { Piagetiana }\end{array}$ & $\begin{array}{l}\text { Alfabetização e } \\
\text { letramento }\end{array}$ & $\begin{array}{l}\text { Construtivista } \\
\text { Piagetiana }\end{array}$ & $\begin{array}{l}\text { Construtivista } \\
\text { Piagetiana }\end{array}$ & $\begin{array}{lr}\text { Perspectiva } & \text { da } \\
\text { alfabetização } & \mathrm{e} \\
\text { letramento } \mathrm{e} & \mathrm{o} \\
\text { encontro de } & \text { várias } \\
\text { teorias } & \\
\text { educacionais. } & \\
\end{array}$ \\
\hline $\begin{array}{l}\text { Como } \\
\text { ocorre(eu) } \\
\text { a } \\
\text { formação }\end{array}$ & $\begin{array}{lr}\text { Orientadores } & \text { ou } \\
\text { coordenadores } & \\
\text { pedagógicos } & \text { que } \\
\text { recebiam a formação e } \\
\text { repassavam } \\
\text { professores. }\end{array}$ & $\begin{array}{lr}\text { Os professores } \\
\text { recebem r } \\
\text { formação por } \\
\text { meio } & \text { de } \\
\text { tutores. } & \end{array}$ & $\begin{array}{lr}\text { Professores } & \\
\text { formadores } & \\
\text { recebem } & \text { a } \\
\text { formação } & \mathrm{e} \\
\text { repassam } & \text { aos } \\
\text { professores. } & \end{array}$ & $\begin{array}{l}\text { Uma equipe recebe } \\
\text { a formação, } \\
\text { repassa aos } \\
\text { coordenadores } \\
\text { pedagógicos e cabe } \\
\text { a eles, divulgar os } \\
\text { preceitos dessa } \\
\text { nova formação aos } \\
\text { professores } \\
\text { alfabetizadores. }\end{array}$ & $\begin{array}{l}\text { Formação } \\
\text { multisseriada. }\end{array}$ \\
\hline
\end{tabular}

Fonte: Barbosa, 2017, p. 69

como norteador dos trabalhos de professores e gestores. Disponível em <http://portal.inep.gov.br/web/provinha-brasil/provinha-brasil.>Acesso em 04/02/2016. 
Percebe-se que ao longo de duas décadas, várias formações continuadas foram oferecidas aos professores alfabetizadores tanto em nível nacional quanto estadual. De certa forma, todas elas impactaram a formação desses professores, pois mesmo que não vivenciaram o exato momento da consolidação de uma dessas formações, elas deixaram marcas nas histórias profissionais de professores e gestores, influenciaram as escolhas e as concepções pedagógicas que adotaram, adotam e/ou adotarão, ou seja, paralelamente às ações pedagógicas, o professor vive processos que influenciam seu modo de ser docente. (NÓVOA, 1992).

Coadunando com Gatti (2008) percebe-se que os cursos de formação continuada apresentam metas pautadas em competências e habilidades, enunciadas como se fossem ingredientes rotulados que, quando adicionados, garantem os resultados almejados. No entanto, segundo a mesma autora, o uso do termo competência e/ou habilidade contornou a dificuldade, em certos círculos, de falar em domínio de técnicas para o trabalho docente, que ficou descartada sob o rótulo do tecnicismo. Desta forma, "Entre os educadores brasileiros, é difícil falar em técnica; bem mais fácil falar em competência” (GATTI, 2008, p.7).

\section{O que fica das formações? Considerações a partir de um curso de FC sobre Geometria do PNAIC}

Como explicitado anteriormente, o objetivo deste texto é traçar uma breve relação com a maneira como professores alfabetizadores compreendem as formações continuadas, tendo como base os depoimentos sobre um curso de FC, com conteúdo de Geometria, oferecido pelo PNAIC.

De posse do entendimento da breve explanação sobre as FC dos quais os sujeitos tiveram acesso direta ou indiretamente, apresenta-se de forma mais detalhada, elementos que possibilitaram essa articulação.

Conforme mencionado anteriormente, este artigo é um recorte de dissertação de mestrado (BARBOSA, 2017) de caráter qualitativo (BOGDAN; BIKLEN, 1994), devido ao fato de esta vertente possibilitar o questionamento dos sujeitos, de modo que percebam como experienciam em suas práticas docentes, como interpretam suas experiências e como se estruturam ao ensinar.

Entre as 97 escolas que atendem ao Ensino Fundamental, na cidade lócus da pesquisa, dezesseis pertencem ao sistema municipal de ensino, trinta e três à rede particular e quarenta e oito à rede estadual. Dentre as dezesseis escolas municipais, foram selecionadas duas para fazerem parte desta amostra. Ambas estão situadas em bairros periféricos, considerados regiões carentes, cuja população, em sua maioria, composta por trabalhadores do setor terciário que recebem benefícios governamentais, tais como bolsa família, por exemplo. $\mathrm{O}$ critério adotado para a escolha foi o Índice de Desenvolvimento da Educação Básica (IDEB) 
dessas escolas, que são classificados como baixos, se comparados às demais do município. Por esses motivos, ações formativas promovidas pela Secretaria Municipal de Educação são constantemente realizadas, visando à elevação desses índices.

As participantes desta pesquisa foram cinco professoras, aqui denominadas pela letra $\mathrm{P}$ (professora) e por números de 1 a 5, de acordo com a ordem que responderam as entrevistas. As idades das mesmas variavam entre trinta e quarenta anos e o tempo de magistério compreendido entre oito e dezesseis anos. Lecionavam, em média, há dez anos no sistema municipal de ensino, participaram da formação em Geometria do PNAIC no ano de 2014, e atuavam como professoras dos anos iniciais, em 2016.

A forma de coleta de dados foi uma entrevista semiestrurada, que durou em média vinte minutos, abordando questões que possibilitaram levantar dados referentes à formação profissional acadêmica, até a formação específica no que diz respeito aos conceitos geométricos e sua relação com o ensino, totalizando vinte e uma questões. Neste artigo o enfoque será em duas delas, visando compreender alguns fatores que as levaram a participar dessas formações e, em quais aspectos, do ponto de vista dos pesquisados, a formação contribuiu (ou não) para o trabalho docente.

As análises realizadas durante a investigação permitiram compreender as possíveis implicações dessas formações na prática pedagógica dos professores estudados. Constatou-se que esses profissionais foram orientados por políticas públicas estaduais e também por formações oferecidas em âmbito nacional. Tais cursos vieram em oposição ao ensino tradicional e adotaram vertentes teóricas apoiadas na perspectiva construtivista piagetiana. Atualmente esta rede municipal de ensino, na qual os professores participantes atuavam, adota outra vertente teórica, a Histórico-Crítica, numa perspectiva vigotskiana. Ou seja, os professores estão sendo conduzidos de forma muito diferente àquela praticada e estimulada em outras formações durante muitos anos e contrárias aos ideais das propostas de ensino da rede pública paulista, que adota uma perspectiva considerada neobehaviorista, baseada na perspectiva de competências e habilidades (PERRENOUD, 2000). Tal fato coaduna-se às ideias de Esteve (1992, p.97), que trata a mudança de paradigma das formações "[...] comparável à de um grupo de actores, vestidos com trajes de determinada época, a quem sem prévio aviso se muda o cenário, em metade do palco desenrolando um novo pano de fundo do cenário anterior".

Desta forma, os professores alfabetizadores desta rede de municipal ensino puderam ter acesso a formações distintas, confirmando o que cita Alarcão (2004, p.11), “[...] a formação continuada tem saltado de modelo em modelo, sem avaliações consistentes e sistemáticas que permitam analisá-los em seus princípios, realizações, resultados e contextos".

No Quadro 1 são apresentadas respostas enunciadas para duas questões elaboradas com o intuito de compreender quais motivos levaram as professoras a participarem deste tipo 
de formação, bem como, o entendimento de cada uma delas sobre a contribuição desta formação ao seu fazer docente. Após refletirem, emitiram suas respostas, cujos recortes estão apresentados.

Quadro 2: Questões sobre a formação continuada do PNAIC

\begin{tabular}{|c|c|}
\hline \multicolumn{2}{|c|}{ Em relação à formação continuada do educador } \\
\hline Questão & Respostas \\
\hline $\begin{array}{l}\text { 1- Cite alguns fatores que o levam } \\
\text { a participar destes tipos de curso. }\end{array}$ & $\begin{array}{l}\text { P1 Acho que é mais para se atualizar mesmo, ir mudando a } \\
\text { prática [...] } \\
\text { P2 [...] O professor nunca deve parar de estudar. Sempre vai ter } \\
\text { alguma coisa que você não conhece [...] } \\
\text { P3 [...] Como trabalhar, as áreas do currículo que a gente tem que } \\
\text { trabalhar. } \\
\text { P4 Para tirar as dúvidas, enriquecer o trabalho, inovação na } \\
\text { nossa prática pedagógica [...] } \\
\text { P5 [...] Tem que ter haver com o que eu trabalho em sala de aula }\end{array}$ \\
\hline \multicolumn{2}{|r|}{ Em relação à formação do PNAIC } \\
\hline Questão & Respostas \\
\hline $\begin{array}{l}\text { 2- Em que aspectos essa } \\
\text { formação contribuiu para o seu } \\
\text { trabalho? }\end{array}$ & $\begin{array}{l}\text { P1 [...] o PNAIC ele veio voltado também à teoria e também para } \\
\text { a prática e isso é muito enriquecedor para o professor em sala de } \\
\text { aula. } \\
\text { P2 Na parte mais prática, eu sempre fui muito de lousa e caderno } \\
\text { e lá eles ensinaram muita coisa prática [...] } \\
\text { P3 [...] No PNAIC, eu pelo menos vi bastante coisa simples, que a } \\
\text { gente podia tá trazendo para sala de aula. } \\
\text { P4 O uso de jogos que foram apresentados no PNAIC e eu não } \\
\text { tinha pensado naquela forma como foi nos mostrado [...] } \\
\text { P5 Contribui assim, de saber como falar com as crianças, como } \\
\text { explicar as formas das figuras (no caso da Geometria) }\end{array}$ \\
\hline
\end{tabular}

Fonte: Autoras, 2020

De acordo com as respostas à questão 1, evidenciou-se que a busca por formação continuada ocorre por dois fatores: devido ao fato de o professor compreender-se em constante aprendizado e para auxiliá-los com questões didáticas de ensino.

Gatti (2008) faz apontamentos nesse sentido, quando expõe que na última década a preocupação com a formação de professores entrou na pauta mundial pela conjunção de dois movimentos: de um lado, pelas pressões do mundo do trabalho, que vem se estruturando em novas condições, num modelo informatizado e com o valor adquirido pelo conhecimento; de outro, a partir dos baixos índices de desempenho dos alunos em avaliações externas, pelos quais os professores são, até certo ponto, injustamente responsabilizados.

Esses, via de regra, responsabilizam o professor pelos baixos índices de aprendizagem dos alunos desconsiderando que ele também é produto de uma formação desqualificada; que está sujeito a condições de trabalho e de remuneração desfavoráveis; e que as políticas públicas educacionais fiam mais 
nos discursos, na retórica, nas intenções, do que em ações efetivas, sistemáticas e de longo prazo. (CORTELA, NARDI, 2015, p.52.

Romanowski (2007) afirma que a formação continuada é uma exigência para os tempos atuais. Desse modo, pode-se afirmar que a formação docente acontece num continuum, iniciada com a escolarização básica, que depois se complementa nos cursos de formação inicial e continuada com instrumentalização do professor para agir na prática social, para atuar no mundo e no mercado de trabalho.

Assim como afirmam Gauthier et al. (1998) o professor possui um reservatório de saberes abastecidos durante toda sua trajetória pessoal, que sofre influências do seu processo de escolarização até a graduação, dos pares, do meio que leciona e da compreensão daquilo que lhes falta para atingir o êxito em suas ações pedagógicas.

Quanto as respostas à questão 2, observa-se que aprovaram os aspectos procedimentais oferecidos pelo curso de FC em relação a Geometria, no qual o mesmo apresentou a teoria (mesmo que brevemente, foram apenas $12 \mathrm{~h}$ de um total de 120h do curso) e as possibilidades de ações de ensino. É possível generalizar que para as participantes desta pesquisa um bom curso de FC deve demonstrar as diversidades de ações pedagógicas frente a um conteúdo, utilizando novos recursos, outras abordagens e não ficar preso aos métodos tradicionais de ensino, na exploração de livros didáticos e exercícios na lousa.

Durante as análises dessas respostas (questão 2), foi possível perceber o uso constante da palavra "práticas" evidenciando algumas marcas ideológicas nas falas dos sujeitos. Com base no entendimento de que não há um discurso que não se relacione com os outros (ORLANDI, 2002), destacam-se, nos discursos aqui encontrados, as marcas de modelos formativos pautados nos ideais da racionalidade técnica, no qual "[...] a atividade profissional consiste na solução instrumental de um problema, feito pela rigorosa aplicação de uma teoria científica ou uma técnica" (SCHÖN 1983, p. 21). Vista por essa vertente, a formação docente é pautada na ideia que após receber determinada formação teórica, sob viés da perspectiva behaviorista, os professores devem aplicá-la, ou seja, o profissional é tido como sendo um técnico do ensino.

Defende-se aqui que nem sempre essa combinação garantirá o êxito no ensino e melhoria na aprendizagem. É necessário o entendimento de teorias referentes à Educação, das críticas teóricas sobre os diferentes modelos formativos para, assim, o educador realizar suas escolhas metodológicas e práticas, refletindo sobre elas, dentro de uma pluralidade metodológica, necessária para o atendimento de diferentes demandas educativas. Ou seja, fazse aqui uma defesa pela racionalidade crítica, superando as racionalidades prática e técnica, distanciando-se do sentido pragmático e dando voz ao caráter político nas diferentes formas de conhecimento e, nas diferentes relações do sujeito com o conhecimento. (ORLANDI, 2016). 


\section{Considerações}

Acredita-se que as reflexões aqui apresentadas permitam compreender as semelhanças encontradas na elaboração dos cursos de formação continuada ao longo das últimas duas décadas no Brasil. Entre elas, estão as influências de concepções tecnicistas nestes cursos, o caráter paliativo de algumas ações, visando sanar problemas genéricos, o uso de abordagens teóricas desconectadas com realidade profissional dos docentes, e/ou a ênfase nos conteúdos procedimentais, a falta de continuidade e a não divulgação de avaliações internas realizadas, visando aprimoramento do processo.

Outro fato observado refere-se aos modelos formativos adotados. Nos cinco programas aqui apresentados, o conhecimento teórico e metodológico que embasaram/embasam tais formações são repassados de grupos em grupos, ou seja, um formador recebe as orientações teóricas e metodológicas de uma IES e as transmite a outro formador que será responsável em fazer a informação chegar aos professores alfabetizadores. Neste processo, que em muito se assemelha à brincadeira do "telefone sem fio", podem ocorrer reducionismo e deturpações de conteúdos e estratégias que resultam em perdas não intencionais, por parte dos tutores, mas talvez intencionais, ou minimamente previstas, por parte dos proponentes, que visando uma economia de dinheiro e tempo adotam, repetidamente, esta dinâmica de trabalho, desconsiderando os dados das avaliações externas que indicam resultados negativos.

As formações continuadas apresentadas visavam/visam o aperfeiçoamento técnico com intencionalidade de formar professores executores de determinações governamentais; que utilizem, segundo prescrições superiores, materiais disponibilizados pelo MEC/Secretarias de Estado e Municípios, pautados em resultados de avaliações externas que, muitas vezes, não possuem neutralidade em seu processo de execução e análise. Neste contexto, cabe ao professor a responsabilidade em atingir os índices educacionais propostos/impostos e, quando não o alcançam, muitas vezes, são responsabilizados pela não efetividade das formações recebidas. Daí, o Estado gestor/avaliador troca os modelos formativos, por vezes fazendo o mais do mesmo, desconsiderando as possíveis influências destas concepções na prática de ensino dos professores.

A partir das respostas dos professores alfabetizadores percebeu-se a significância conferida aos cursos de formação continuada que exploram a parceria teoria-prática, com ênfase na prática. Ou seja, que trabalham conceitos teóricos de forma mais aligeirada e apresentam situações em que estas teorias podem manifestar-se no ensino em sala de aula. Também neste sentido, evidenciam-se os traços de uma formação compreendida muito mais em relação à racionalidade técnica do que à crítica.

Tais apontamentos direcionam o entendimento para a constatação de um cenário que induz a desintelectualização do professor, uma vez que todas as formações primam pela 
formação técnica em detrimento à formação crítica e, embora citem que há momentos para troca de experiências e reflexões, estas são, muitas vezes, esvaziadas em decorrência do tempo de formação oferecido. O resultado dessas ações, conforme elucidado, são tentativas de práticas de ensino diferenciadas, que como receitas, seguem uma orientação pré-estabelecida, mas esbarram no campo conceitual, deixando de desenvolver explicações mais detalhadas sobre o conteúdo.

Sendo a formação continuada fundamental para o desenvolvimento profissional dos professores, faz-se necessário que os modelos formativos sejam reestruturados, de fato, para promover a reflexividade crítica sobre conhecimentos e práticas e a (re)construção permanente de uma identidade profissional. Mais do que formações continuadas, é preciso investir numa formação inicial de qualidade, para que as continuadas tenham que dar conta de aspectos complementares, e não daqueles que são a base profissional.

\section{Referências}

ALARCÃO, I. Professores reflexivos em uma escola reflexiva, $3^{\mathrm{a}}$ ed. São Paulo: Cortez, 2004.

AlVARADO-PRADA, L. E.; FREITAS, T. C.; FREITAS, C. A. Formação continuada de professores: alguns conceitos, interesses, necessidades e propostas. Rev. Diálogo Educ., Curitiba, v. 10, n. 30, p. 367-387, maio/ago. 2010.

BARBOSA, A. P. R. Formação continuada de professores para o ensino de Geometria nos anos iniciais: um olhar a partir do PNAIC.Dissertação (Mestrado em Educação para Ciência) Faculdade de Ciências. UNESP, Bauru, 2017.

BRASIL. Plano Nacional de Educação. Lei 10. 172/o1 Brasília: Plano: MEC/INEP, 2001.

Ministério da Educação. Secretaria de Educação Fundamental. Letra e VidaPrograma de Formação de Professores Alfabetizadores: coletânea de textos. V.1. São Paulo: SEE/SP, 2003.

Lei Federal n. 11.274, de 06 de fevereiro de 2006. Altera a redação dos arts. 29, 30, 32 e 87 da Lei n. 9.394/96, de 20 de dezembro de 1996, que estabelece as Diretrizes e Bases da Educação Nacional, dispondo sobre a duração de 9 (nove) anos para o Ensino Fundamental, com matrícula obrigatória a partir dos 6 (seis) anos de idade. Diário Oficial da União, Brasília, n. 27, p. 1-2, 07 fev. 2006.

Secretaria de Educação Básica. Diretoria de Apoio à Gestão Educacional. Pacto Nacional pela Alfabetização na Idade Certa: Apresentação / Ministério da Educação, Secretaria de Educação Básica, Diretoria de Apoio à Gestão Educacional. Brasília: MEC, SEB, 2014.

BOGDAN \& BIKLEN. Investigação Qualitativa em Educação: uma introdução à teoria e aos métodos. Coleção Ciências da Educação. Portugal, Porto Editora, 1994.

CORTELA, B.S.C; NARDI, R. Expectativas de docentes formadores frente a um processo de reestruturação curricular num curso de licenciatura em Física. In: NARDI, R; CORTELA, B.S.C (Org.). Formação inicial de professores de Física em universidades públicas: estudos realizados a partir de reestruturações curriculares. São Paulo: Livraria da Física, 2015, p.47-74.

ESTEVE, J.M. Mudanças sociais e função docente. In NÓVOA, A. Profissão professor. Porto, PT: Porto Editora, 1992. 
FERREIRO, E.; TEBEROSKY, A. Psicogênese da Língua Escrita. Artmed Editora. Porto Alegre. 1999

GATTI, B. A. Análises das políticas públicas para a formação continuada no Brasil, na última década. Revista Brasileira de Educação, v.13, nº 37, jan./abr. 2008. et al. Políticas docentes no Brasil: um estado da arte. Brasília: UNESCO, 2011

GAUTHIER et al. Por uma teoria da pedagogia: pesquisas contemporâneas sobre o saber docente. Ijuí: Ed. Unijuií, 1998.

NÓVOA, A. Formação de professores e profissão docente. In. Os professores e sua formação. Lisboa: Dom Quixote, 1992.

PERRENOUD, P. Dez novas competências para ensinar. Porto Alegre: Artmed, 2000.

RAMOS. G.P.; FERRARONI. D.S. PROFA: desconstruindo o tradicional em busca de um consenso construtivista. Comunicações. Piracicaba, v. 16, n. 2, p. 73-83, jul.-dez. 2009.

ROMANOWSKI, J. P. Formação e Profissionalização docente. Curitiba: Ibpex, 2007.

ORLANDI, E. P. (2002). Análise do Discurso: Princípios \& Procedimentos. $4^{\mathrm{a}}$ ed. Campinas, SP: Pontes (2016). Educação e Sociedade: o discurso pedagógico entre o conhecimento e a informação. ALED, edição 16 (2), p.68-80.

SÃO PAULO. Secretaria da Educação. Resolução SE no 86, de 19 de dezembro de 2007. Institui para o ano de 2008, o Programa "Ler e Escrever" no ciclo I das Escolas Estaduais de Ensino Fundamental da Coordenadoria de Ensino da Região Metropolitana da Grande São Paulo. 2007 Disponível em:http://siau.edunet.sp.gov.br/ItemLise/arquivos/86_07.HTM?Time=16/o5/201 6\% 2019:10:41> Acesso em 11/05/16

SARAVIA, E., FERRAREZI, E., (Org.). Políticas públicas. V I. Brasília: ENAP, 2006.

SAVIANI, D. Pedagogia histórico-crítica: primeiras aproximações. 11. ed. rev. Campinas: Autores Associados, 2013.

SCHÖN, D. (1983). The reflective practitioner. New York: Basic Books.

SILVA, C. S. R.; CAFIEIRO, D. Alfabetização e letramento de crianças de seis anos: as políticas para implantação do Ensino Fundamental de nove anos. Intermeio, Campo Grande, v. 16, n. 32, p. 27-48, jul./dez. 2010.

SOARES, B. M. O que é letramento e alfabetização. In. Letramento, um tema em três gêneros. Belo Horizonte, Editora Autêntica 1999.

SOUZA. C. Políticas públicas: uma revisão da literatura. Sociologias, Porto Alegre, n.16, jul.dez., 2006.

TARDIF, M. Saberes docentes e a formação profissional. 17. Ed.- Petrópolis: Vozes, 2014

Biografia Resumida

Aline Pereira Ramirez Barbosa: Pedagoga, Mestre em Educação para a Ciência pela UNESP- Universidade Estadual Paulista, Bauru, doutoranda pela mesma instituição e coordenadora 
pedagógica do Ensino Fundamental I de uma rede pública de ensino. Integrante do Grupo de Pesquisa em Ensino de CiênciasGPEC, Unesp/Bauru.

Lattes: http://lattes.cnpq.br/7871167384185330

Contato: aline.ramirez-barbosa@unesp.br

Beatriz Salemme Corrêa Cortela: Doutora e Mestre em Educação para a Ciência pela UNESP- Universidade Estadual Paulista, Bauru, docente do departamento de Educação e colaboradora do Grupo de Pesquisa em Ensino de Ciências- GPEC, Unesp/Bauru. Lattes: http://lattes.cnpq.br/4503845701410945

Contato: beatriz.cortela@unesp.br 